\title{
Financial planning for the decommissioning of a nuclear power plant
}

\author{
R. Sjöblom ${ }^{1,2}$, A. Cato ${ }^{3} \&$ S. Lindskog ${ }^{3}$ \\ ${ }^{1}$ Tekedo AB, Sweden \\ ${ }^{2}$ Luleå University of Technology, Sweden \\ ${ }^{3}$ The Swedish Radiation Safety Authority, Sweden
}

\begin{abstract}
After their service life is over, nuclear power plants must be decommissioned. Accordingly, Sweden has a system with segregated funds to cover the costs. Payments to the funds are dictated by the results of recurrent cost estimates. Recently, differences have been observed between different estimations for the Barsebäck BWR:s. Therefore, the Swedish Radiation Safety Authority, who oversees the system, has commissioned the present study with the objective to investigate the reasons. The work comprises analyses of generic deviances as well as specific ones. It was found that the variations are within the ranges observed elsewhere, but that the precision in comparisons between different reactors can be improved. No new cost raisers were identified for the Barsebäck reactors. It was found that the cost estimation community strongly recommends the parametric method for early estimates whilst the cost calculations on decommissioning are mostly based on the bottom-up method. It is proposed that the parametric method be attempted for comparison between different reactors. Keywords: decommissioning, nuclear, power, waste, financing, fund.
\end{abstract}

\section{Introduction}

\subsection{The Swedish nuclear power programme(s)}

"Only six countries took part in the rush to build the first nuclear power stations - the United States, the United Kingdom, France, the Soviet Union, Canada and Sweden. All other countries were in due course to turn to one or another of these pioneers for assistance with their first power reactors and subsequent nuclear 
construction programs." This quote is taken from a compilation of the history of nuclear technology and nuclear power development published by the American Nuclear Society [1].

Actually, Sweden had two consecutive nuclear power programmes: "the Swedish strategy" (in Swedish: "den svenska linjen") with tank-type heavy water PWR:s (pressurized water reactors), and the modern programme with mainly BWR:s (boiling water reactors).

The first Swedish nuclear reactor was started in 1954. It was used mainly for research purposes, and provided valuable input also to subsequent research reactors and other nuclear technology facilities. The developments lead to the design and construction of the Ågesta nuclear power reactor which was in operation during 1963-1973. It was a heavy water moderated reactor that could operate on natural uranium (without enrichment). It had a total capacity of 65 MW, $10 \mathrm{MW}$ of which was for electricity generation, and $55 \mathrm{MW}$ was for district heating.

Some of the facilities erected and used under "the Swedish strategy" have been decommissioned while others still constitute a nuclear legacy. This has been described by the present authors in previous publications [2-5].

The signing of the contract for Oskarshamn 1 in 1965 marked a shift of paradigm, since this reactor was to be of BWR type. There were a number of good technical and economical reasons for this shift including e.g. lower prices for enrichment services, and higher power output per unit reactor tank volume for BWR:s. There were a lot of discussions as well as controversy over the route to take, and e. g. the managing director of AB Atomenergi (now Studsvik AB), Harry Brynielsson predicted in 1970 that Sweden would have its first fast reactor in around 1980 [6]. AB Atomenergi initially had the national role to develop and construct nuclear power reactors, and has been instrumental in the advancement of nuclear technology in Sweden.

A total of 11 nuclear power reactors of Swedish ASEA-ATOM design were built, 9 in Sweden (at Barsebäck near Lund, Oskarshamn, Ringhals near Varberg and Forsmark near Östhammar) and 2 in Finland (at Olikluoto outside Rauma). In addition, three PWR:s of Westinghouse design were built at Ringhals. The reactors were taken into operation during 1972-1985. The reactors are still in operation except the two at Barsebäck which have been shut down. There are significant differences in design between the early and late ASEA-ATOM reactors, but Oskarshamn 2 and Barsebäck 1 and 2 are very similar.

The historical developments in Sweden are described in [2, 7].

\subsection{Swedish nuclear power plant cost calculations}

AB Atomenergi published 517 reports in its main and open series during 1956 1977 , none of which deals with decommissioning. The first records found on Swedish activities on decommissioning are from the year 1975 when the AKA public enquiry on nuclear waste was published [8-10], and when Swedish experts participated in an International Atomic Energy Agency (IAEA) meeting [11]. 
The AKA enquiry proposed amongst other things that all costs to cover environmental liabilities - waste management and disposal, decommissioning, and research - should be paid by the nuclear utilities. In 1978, a law was passed that made clear that funds set aside by the utilities to cover such costs should not generate taxation. Allocation of money to such funds started in the same year. Since 1981, the funds are segregated and managed by the Government.

In 1979, the Swedish Nuclear Fuel and Waste Management Company (SKB, then SKBF/KBS) published their first report [12] on cost estimations for decommissioning of Swedish nuclear power reactors. Reference units in this study are Oskarshamn 2 and Barsebäck 1 which are very similar in their designs.

Since then, SKB has published recurrent cost estimates, and they have formed the basis for their proposal to the Authority (now the Swedish Radiation Safety Authority, SSM). After review of the SKB proposal, the SSM has proposed the level of the fee to be paid on the nuclear electricity to the Government which has made the decisions.

Since many years, SKB has commissioned what today is Westinghouse Electric Sweden AB (originally ASEA-ATOM) to support them in their estimations of the costs for decommissioning of the nuclear power plants, see e. g. $[13,14]$. Recently, SKB has, in addition, turned to TLG Services, Inc. for an independent estimate [15].

The total cost according to the estimates [12-15] are presented in Table 1.

Table 1: Decommissioning cost estimates for one of the reactors at Barsebäck. Updating to today's monetary value has been made using the Swedish consumer index. The estimate for the year 2004 is based on a comparison with Oskarshamn 3.

\begin{tabular}{|l|c|c|c|c|c|c|c|}
\hline & $\begin{array}{c}\text { MSEK } \\
1979\end{array}$ & $\begin{array}{c}\text { MSEK } \\
2004\end{array}$ & $\begin{array}{c}\text { MSEK } \\
2005\end{array}$ & $\begin{array}{c}\text { MSEK } \\
2012\end{array}$ & $\begin{array}{c}\text { M€ } \\
2012\end{array}$ & $\begin{array}{c}\text { M£ } \\
2012\end{array}$ & $\begin{array}{c}\text { M\$ } \\
2012\end{array}$ \\
\hline SKB 1979[12] & 500 & & & 1581 & 178 & 233 & 146 \\
\hline SKB 2004[13] & & 802 & & 912 & 102 & 134 & 84 \\
\hline TLG 2008[15] & & & 1632 & 1848 & 208 & 272 & 171 \\
\hline
\end{tabular}

The substantial differences between the different estimates have prompted SKB to investigate the reasons for the difference, see [16] which is discussed in Sections 4.2 and 5, and to propose a substantial increase in the fee (by $70 \%$ ).

The substantial differences have also prompted the SSM to carry out independent studies. One such study is [17] which has been carried out in parallel with the present work.

\section{Objective}

The objective of the present work is as follows:

- To search for generic reasons for the deviations 
- To search for reasons for the deviations specific to the work on the Barsebäck nuclear power plant

- To qualitatively analyse the significance of potential cost raisers

- To attempt to identify possibilities for improvement

- To identify and discuss lessons learned that may be of interest outside the circle of nuclear decommissioning specialists.

The objective was to be achieved through information searches in combination with visits to the Barsebäck nuclear power plant and discussion with responsible officers.

\section{International perspective}

\subsection{Calculation methodology}

Many textbooks and other authoritative documents, e. g. [18-20], bring up the necessity of a step by step approach and the associated need to select appropriate estimation methodology in each step, and an example is provided in Table 2. Information can also be found on the internet pages of the Association for the Advancement of Cost Engineering (AACE International) and the International Society for Parametric Analysis (ISPA).

Table 2: $\quad$ Stage versus type of estimation method $[17,18]$.

\begin{tabular}{|l|l|l|}
\hline Type of estimate & Accuracy & Recommended method \\
\hline $\begin{array}{l}\text { Order of } \\
\text { magnitude }\end{array}$ & $-30 \%$ to $+50 \%$ & $\begin{array}{l}\text { Parametric technique, others } \\
\text { possible }\end{array}$ \\
\hline Budget estimate & $-15 \%$ to $+30 \%$ & All possible \\
\hline Definite estimate & $-5 \%$ to $+15 \%$ & $\begin{array}{l}\text { Bottom-up technique, others } \\
\text { possible }\end{array}$ \\
\hline
\end{tabular}

The bottom-up technique implies that deterministic sums are made over all work and material that goes into a project to give the total sum. This works well when all the items have been identified and when the costs of each of them is known, e. g. from binding quotations from suppliers. Historic data from previous projects can also be used. It is recommended that the bottom-up technique be used at late stages of planning, and for the most accurate estimates.

Early on in the planning, the bottom-up technique is either insurmountably tedious or provides results that are systematically too low (or at least grossly erroneous). The main reason for systematically low errors is probably that some of the items are missing.

For early estimates, data from previous projects can be analysed to provide insight regarding what parameters influence the price and how (not necessarily linearly). Inserting values for the parameters for the new object in question then renders the estimated price. In other words, and according to the Parametric Estimating Handbook [21] issued by ISPA: "Parametric estimating is a 
technique that develops cost estimates based upon the examination and validation of the relationships which exist between a project's technical, programmatic, and cost characteristics as well as the resources consumed during its development, manufacture, maintenance, and/or modification".

The handbook [21] also proposes that the following steps be followed when a parametric model is to be developed:

- Database development;

- Model Requirements;

- Resolution of model architecture and data availability;
- Model development;

- Model calibration and validation;

- Model documentation;

- Model updating."

The development of such a model can be cumbersome and may require access to several finished projects, not least for the calibration and validation. However, once a model has been developed, the actual estimation is very quick. It is claimed in the Handbook [21] that "early costing cannot be done effectively any other way".

Regardless of what method is applied, estimates should always include uncertainty, and this is constantly reiterated by e. g. AACE International.

\subsection{Decommissioning cost calculations}

A brief review of the early history of cost estimations for decommissioning of nuclear power reactors can be found in [22]. The topic caught increased interest in the 1970's after a number of decommissioning projects on various nuclear research facilities, and the decommissioning of the Elk River 24 MWe BWR which was in operation during 1962-1968. This nuclear power reactor was the first one to be totally dismantled and removed from the site at around the year 1974. The total cost was M\$ 6.15 which corresponds to MSEK 157, M€ 18, M\$ 23 and M£ 11 in today's currencies (using the exchange rate for the year 1974 and the Swedish consumer price index).

According to Reference [22], early attempts to estimate costs for larger and more ordinary sizes of nuclear reactors by simply scaling the costs for Elk River using the ratio in thermal power resulted in outcries against nuclear power development which, in turn, prompted the nuclear industry to fund more specific and detailed studies. It was claimed that such scaling would give results that rivalled even the cost of construction!

A few years later, the Unit Cost Factor (UCF) method was developed based largely on the comprehensive knowledge on decommissioning technology by LaGuardia [23], and an example of a description of the method can be found in Chapter 12 in [24], see also [25].

The UCF method is basically a bottom-up method but with wide possibilities to include various multipliers / factors in the input to reflect "difficulty". Thus, the output is strongly dependent on the basic unit factors which are to be determined from finished projects, and the experience of the person establishing 
the input in assessing "difficulty" in concordance with "incurred" difficulties in previous projects.

Presentations from international conferences on decommissioning of nuclear facilities have been briefly compiled, and it has been found that the unit cost factor method or similar, i.e. bottom-up methods, have been used in the vast majority of cases. Papers [26, 27] are exceptions found. A number of reports on decommissioning have been published by IAEA, OECD/NEA (OECD Nuclear Energy Agency) and the EU, and parametric methods are discussed in some of them.

\subsection{The California experience}

A search was made in the international literature in order to find out if similar deviances have been observed and studied elsewhere. This is indeed the case, and there are many references. They include $[28,29]$ in which some international data is compiled. It is put forward that there should be differences between different reactors depending on a number of circumstances. Improvement is expected by providing check lists of cost raisers as well as a standardized structure for costing.

Nonetheless deviances persist and exceed by far what might reasonably be expected considering the many terms and summations involved. This issue will be illuminated in the following by an example from the state of California.

The California Public Utility Commission (CPUC) recurrently reviews and sets collection amounts for the nuclear utilities that provide service to customers in California. It was agreed with these utilities that a panel be established to evaluate the planning for decommissioning and associated cost calculations which form the basis for financial decisions. The panel report and a summary can be found in References [30] and [31], respectively. The panel comprised three highly experienced experts on nuclear decommissioning at a managerial level, including Mr Geoffrey Griffiths of TLG services, Inc., [30] who also approved the TLG report on Barsebäck [15].

Some examples of the findings of the panel are as follows:

- Any conclusions about future decommissioning costs "involve a significant amount of informed speculation about events that will only be fully understood in the future"..." and which may resemble historical events to a greater or lesser degree as circumstances change."

- The Panel found substantial barriers to comparing prior decommissioning experiences because reported estimates and costs from around the country are not always public, or even similar in what activities are included and the information disclosed.

- With the exception of Rancho Seco, all actual costs appear to exceed estimated costs by varying margins, e.g., Connecticut Yankee exceeded estimates by $82 \%$ and SONGS 1 by $32.5 \%$. (However, the Panel presented these results more as indications than actual factual findings due to the challenges of comparison.) 
- There were numerous problems in obtaining accurate and comparable figures. For example, some information is withheld as proprietary, public records can be incomplete, and estimates may not include identical activities or may even omit key elements such as site restoration.

- Eight items were identified that account for $99.4 \%$ of the cost difference between SONGS 2 and 3, and Diablo Canyon 1 and 2.

- By a large margin, the assumed site condition at the end of decommissioning is the primary difference between the estimates.

- Historical experience in the U.S. has provided no consensus on the best way to decommission a nuclear plant because every site has different challenges, technology is improving, and new ideas are borne from experience.

- The Panel was asked to develop a common format for decommissioning cost estimates that would result in greater transparency and comparability. However, the fact that cost estimators use proprietary and substantially different decommissioning cost models to develop their estimates, combined with the unique aspects of decommissioning SONGS, make a common cost model impractical.

- The panel found a key error that reduced the Palo Verde estimate by about half. It took a lot of digging by the Panel and SCE to figure out that a double counting of waste volume had occurred.

It might be tempting to conclude that the challenges involved in estimating costs for decommissioning are such that the results are generally unreliable. This need not be the case, however, as shown by LaGuardia [32], founder of TLG Services who carried out the study on Barsebäck [15]. He reported [32] an agreement between calculated and incurred costs of $8.8 \%$ for Maine Yankee (880 MWe PWR), and about $6 \%$ for Big Rock Point (60 MWe BWR). The systems that were compared were well defined.

\section{The Barsebäck nuclear power plant}

\subsection{Background}

The Barsebäck Nuclear Power Plant comprises two BWR reactors of ASEAATOM design. They had each a thermal capacity of $1800 \mathrm{MWt}$ and an electric capacity of $615 \mathrm{MWe}$. The reactors Barsebäck 1 and 2 were in operation during 1975-1999 and 1977-2005, respectively.

The Barsebäck decommissioning project has been presented to the international community on several occasions, see e. g. [33], and in September, 2011, Barsebäck arranged in collaboration with EPRI (Electric Power Research Institute) an international workshop in Lund, Sweden. Planning and various prestudies are in progress, and the actual dismantling is expected to commence in about five years. 


\subsection{Cost calculations}

The cost estimation studies [12-15] that prompted the present work is described in Section 1.2 which includes a compilation of the results in Table 1.

The early SKB [12] and the TLG [15] studies are based on the two (mutually very similar) reactors at Barsebäck. The other studies [13-14], made by SKB/Westinghouse, are based on detailed studies of the Oskarshamn 3 reactor. The Oskarshamn 3 reactor is also a BWR with ASEA-ATOM design, but more modern (commissioned in 1985) and larger (3300 MWt as compared to Barsebäck 1 and 2 with $1800 \mathrm{MWt}$ ). According to [13], figures for the Barsebäck reactors are obtained from those for Oskarshamn 3 reactor by using the ratio of estimated need for resources for each type of equipment. The scaling is based on the differences in size and construction/design of the different units.

The differences observed between the SKB/Westinghouse estimates [13-14] and those of TLG [15] prompted SKB to make a comparison [16] between a Barsebäck reactor and Oskarshamn 3, and the main conclusions are as follows:

- The correlation between decommissioning cost and thermal power (related to the scaling made by SKB) is weak. It is pointed out that NRC (United States Nuclear Regulatory Commission) uses a first order equation that implies that the difference to be expected (for 3300 vs. $1800 \mathrm{MWt}$ ) should be only $11 \%$.

- There are differences in what facilities are included.

- Cost of management and insurance is lower in Sweden.

It is found that after correction for these bullets, the agreement between the Oskarshamn 3 estimate and that of one of the Barsebäck reactors is well within that required for a budget estimate according to Table 2 .

\subsection{Cost raisers}

The international information search (see Section 3) as well as previous work by the present authors [3] indicate that specific items or parameters - cost raisers may have a significant influence on costs.

Two plant visits were made and meetings were held with responsible officers at Barsebäck in order to get amongst other things a perspective on the cost estimates, and to discuss any potential cost raisers.

It was felt, e. g., that there are difficulties in finding good data on costs, that it is difficult to compare different estimates, and that conditions in Sweden are somewhat different from those elsewhere, including the USA.

A number of potential cost raisers were analysed, and it could be concluded in the vast majority of cases that surprises are not to be expected. For instance:

- All piping and vessels are made of stainless steel with good records as well as samples on the composition.

- All concrete surfaces are covered by epoxy paint.

- The primary system has been decontaminated so the background is low and this facilitates identification of any hot spots.

- There have been no incidents with any apparent influence on decommissioning. 
- There are no active pipes buried directly in the soil.

- Asbestos has already been removed for the most part.

- There have only been few fuel leaks.

One potential cost raiser remained: contaminated soil under one of the auxiliary buildings. This is difficult to investigate beforehand. The cost increase may be insignificant or large.

\section{Discussion and conclusions}

As described in Section 3.2, it has been known since the inception of nuclear power plant decommissioning cost calculations in the 1970's that an assumption of proportionality between the cost and the thermal power can give rise to considerable systematic errors. Reference [22] instead puts forward that a linear equation be used, and this is actually what the NRC uses, as reiterated in the recent SKB report [16]. Mr McGrath at EPRI presented a comparative study on incurred decommissioning costs at the joint EPRI/Barsebäck workshop mentioned above, and showed that the link between size and cost is weak. The present authors have earlier found such a proportionality inappropriate, and also pointed out the necessity of sufficient similarity between plants from which data is taken and the plant for which calculations are to be made [2, 4]. It was proposed that a set of linear equations be used instead for what may be regarded as a simple parametric modelling.

It is intriguing to find that although most cost estimations nowadays are made at an early stage and for the purpose of assuring sufficient financing, the method used is of the type recommended for late stages. Plausible explanations may include history, where a couple of decades ago calculations were largely made in conjunction with decommissioning operations. Another possibility may be contrary to the usual case for new build - that the project is certain, and the bottom-up method will have to be used eventually. Moreover, although sufficient data exist for nuclear power plant parametric modelling, such work may be impeded or made impossible by reluctance to share data. Of course, the UCF method includes features for scaling, and there are check lists to avoid neglecting certain cost raisers. On the other hand, places like Sellafield in the UK and Hanford in the US with huge numbers of nuclear installations may benefit greatly from their use of parametric methods [26-27].

It should not have come as much of a surprise that Swedish cost estimates are low in an international comparison since this was published by OECD/NEA already in 2003 [29]. They found "that the cost values provided for Olkiluoto in Finland and Oskarshamn 3 in Sweden were three to four times lower than the next lowest value".

It is obvious from the discussion on size above that this implies that the costs for small reactors such as Barsebäck 1 and 2 are considerably more likely to be underestimated than those for large ones like Oskarshamn 3. This situation is different from that in 1979 [12], when the reactors Barsebäck 1 and Oskarshamn 2 , both then at around $600 \mathrm{MWe}$, were the references. 
The analysis by the present authors has unveiled nothing that would contradict the TLG report [15] as being a good representative for the state of the art. A minor comment might be that it would have been advantageous for the reader if the numerous limitations and reservations would also have been compiled in a separate part of the report.

In an international perspective, see especially Section 3.3, the differences can be said to be within the ranges of what is presented elsewhere. Nonetheless, and based on e. g. [32] and the discussion in Section 3.3, much better agreements between different calculations as well as between calculated and incurred costs should be attainable. E. g. Reference [2] puts forward that an appropriate target might be $\pm 20 \%$, at least in favourable cases.

The analysis together with members of staff at Barsebäck unveiled no significant cost raisers to the authors, with the exception of the previously reported [15] contamination of soil that is difficult to examine at present.

It appears as reasonable, that SKB either undertakes individual cost studies of the ASEA-ATOM reactors, as put forward in [16], or improves the method for inter-comparison in which case the method ought to be validated [21].

It should be recognized that the decommissioning of the Barsebäck reactors, in a few years time, offers excellent opportunities for the further development of cost calculation methodology for other ASEA-ATOM reactors. The information compiled in the present paper clearly supports a suggestion that parametric methods be included in any such work.

The present example of more than 30 years of cost estimations for the Barsebäck reactors, illustrates some of the challenges that one may face whilst fulfilling obligations under the polluter pays principle. Awareness and legislation have come later in other "sectors" of environmental liabilities. It is hoped that the present paper will support work towards sufficiently early technical and financial planning with sufficient quality also in other areas.

\section{Acknowledgement}

The authors wish to express their sincere gratitude to members of staff at the Barsebäck Nuclear Power Plant for generously sharing their knowledge and experience. Nonetheless, the authors take full responsibility for the content of this paper.

\section{References}

[1] Controlled nuclear chain reaction, the first 50 years. American Nuclear Society, 1992.

[2] Lindskog, S., and Sjöblom, R., Regulation evolution in Sweden with emphasis on financial aspects of decommissioning. Decommissioning Challenges: an Industrial Reality? Sept. 28 to Oct.2, 2008 - Avignon, France.

[3] Andersson, I., Backe, S., Iversen, K., Lindskog, S., Salmenhaara, S. and Sjöblom, R., Cost calculations for decommissioning and dismantling of 
nuclear facilities. Nordic Nuclear Safety Research, Project NKS-R, Report number NKS-165, July 2008.

[4] Sjöblom, R., Sjöö, C., Lindskog, S. and Cato, A., Early stage cost calculations for determination and decommissioning of nuclear research facilities. The 10th International Conference on Environmental Remediation and Radioactive Waste Management. Glasgow, UK, 4-8 September, 2005.

[5] Lindskog, S. and Sjöblom, R, Division of nuclear liabilities between different license holders and owners. Proceedings of the 14th International Conference on Environmental Remediation and Radioactive Waste Management, ICEM2011, September 25-29, 2011, Reims, France.

[6] Brynielsson, H., Nuclear energy in Sweden - 1970. In Rastogi, B. P., editor. Proceedings of the seminar on nuclear power. Published by the Department of Atomic Energy, Government of India.

[7] Söderberg. O., "In the shadow of the nuclear power debate around $1980-$ thoughts on the birth of the finance system of today." (In Swedish). In "Nuclear waste - costs and financing" (Swedish title: Kärnavfall kostnader och finansiering). Swedish National Council for Nuclear Waste. SOU 2005:83.

[8] Radioactive waste. Interim report about low and intermediate level radioactive waste from the AKA public investigation. (In Swedish) Department of Industry, Ds I 1975:8.

[9] Spent nuclear fuel and radioactive waste. A summary report given by the Swedish Government committee on radioactive waste. AKA public investigation. (English summary of AKA Reports I-III in Swedish)) Department of Industry, SOU 1976:32.

[10] Spent nuclear fuel and radioactive waste. Parts I and II. AKA public investigation. (In Swedish) Department of Industry, SOU 1976:30 and SOU 1976:31.

[11] Decommissioning of nuclear facilities. Report of a technical committee meeting on decommissioning of nuclear facilities organized by the International Atomic Energy Agency and held in Vienna, 20-24 October, 1975. IAEA-179.

[12] Techniques and costs for decommissioning of Swedish nuclear power plants. (In Swedish). SKBF/KBS (now SKB) Teknisk Rapport 19-21, 1979.

[13] Hedin, G., Gustavsson, B. and Carlsson, J., Techniques and costs for decommissioning of Swedish nuclear power plants. (In Swedish). SKB R-04-44, Svensk Kärnbränslehantering AB, 2004.

[14] Gustavsson, B., Hedin, G., Johnsson, H., Cassidy, C. and Swenson, B., Swedish BWR Reference Plant Decommissioning Study. Westinghouse Report SEP 06-055, rev 0, Westinghouse Electric Sweden AB, 2006.

[15] Decommissioning Cost Analysis for Barsebäck Nuclear Station. Document S33-1567-002, Rev. 0, TLG Services, Inc, 2008.

[16] Hansson, B. and Jönsson, L.-O., Comparative analysis of the Oskarshamn 3 and Barsebäck site decommissioning studies. SKB Report R-09-55, January, 2009. 
[17] Marelius, F. and Keyser, P., Decommissioning costs for Barsebäck. Calculation of uncertainties and review of the cost estimates for the decommissioning of Barsebäck. The Swedish Radiation Safety Authority, Report SSM2011-153-29.

[18] Peters, M. S. and Timmerhaus, K. D., Plant design and economics for chemical engineers. McGraw-Hill, Inc., 1991.

[19] Humphreys, K. K. and English, L. L., editors, Project and cost engineers' handbook, 3rd edition. Marcel Dekker, Inc., 1993.

[20] Financial aspects of decommissioning. IAEA-TECDOC-1476. November 2006.

[21] Parametric estimating handbook, 4th edition. International Society for Parametric analysis, April, 2008.

[22] Smith, R. I., Estimation of decommissioning costs: history and status. Energy Information Administration Workshop in Nuclear issues: Current and Future. Washington D. C., November 12, 1992.

[23] LaGuardia, P. E., Decommissioning methods and equipment. In Osterhout, M. M., Decontamination and decommissioning of nuclear facilities. Plenum Press, 1979.

[24] Taboas, A. L., Moghissi, A. A. and LaGuardia, T. S., Editors, The decommissioning handbook. ASME Press, 2004.

[25] International Structure for Decommissioning Costing (ISDC) of Nuclear Installations. OECD/NEA, Paris 2012.

[26] Murphy, L. T. and Hickey, M., Parametric cost estimates for an international competitive edge. WM'06 Conference. February 26 - March 2, 2006. Tucson, Arizona, USA.

[27] Deiters, G., Parametric modelling of decontamination and decommissioning costs using MCACES Gold. Cost Engineering, Vol. 39, No. 3 March, 1997.

[28] Decommissioning of nuclear facilities. An analysis of decommissioning cost estimates. OECD/NEA, Paris 1991.

[29] Decommissioning of nuclear power plants. Policies, strategies and costs. OECD/NEA, Paris 2003.

[30] Filing by Southern California Edison Company's (U 338-E) of independent panel report. A.09-04-009 and A.09-04-007, both filed April3, 2009. Final report of the Independent Panel filed on March 1, 2011.

[31] Decision adopting recommendations of the independent panel on nuclear decommissioning costs, estimates, assumptions and format. (Contains a summary of the panel report). Decision 11-07-003 July 14, 2011, Public Utilities Commission of the State of California.

[32] LaGuardia, T. S., Well-Founded Cost Estimation Validated by Experience. Safe, efficient and cost-effective decommissioning, a NEA International Workshop. Rome, September 6-10, 2004.

[33] Lorentz, H., Barsebäck NPP in Sweden - Decommissioning Project. Waste Management 2009 Conference, March 1-5, 2009, Phoenix, Arizona, USA. 